\title{
A comparative study of patient sitters with video monitoring versus in-room sitters
}

\author{
Janet Davis ${ }^{1}$, Mary Kutash ${ }^{1}$, James Whyte IV ${ }^{* 2}$ \\ ${ }^{1}$ Tampa General Hospital, Tampa Florida, United States \\ ${ }^{2}$ College of Nursing, The Florida State University, Tallahassee Florida, United States
}

Received: February 4, 2016

DOI: $10.5430 /$ jnep.v7n3p137
Accepted: May 17, 2016

Online Published: November 18, 2016

\begin{abstract}
Background/Objective: Use of in-room sitters to prevent patient's fall or injury is widespread in hospitals. This practice, however, is expensive, seldom reimbursed, controversial in the literature, and not supported by a strong body of evidence. The objective of this study was to determine the prevalence of patient falls and self-harm using in-room sitters and video monitoring and associated costs.

Methods: In-room sitters and video monitoring was studied in two adult, medical surgical units, using an evaluative research design, with quasi-experimental approach. Descriptive statistics and independent samples $t$ tests were performed for analysis. Results: The study identified no statistically significant difference in the prevalence of falls or self-harm events when video monitoring was used to provide constant observation. There was statistically significant lower cost per patient day with video monitoring.

Conclusions: Video monitoring is less expensive than sitters and does not impose a patient safety risk for falls or self-harm.
\end{abstract}

Key Words: Video monitoring, Patient sitters, Patient safety, Nursing management

\section{INTRODUCTION}

The initial Institute of Medicine report illustrated the need to reduce errors and adverse patient events related to the administration of care in hospitals within the United States. ${ }^{[1]}$ Following this report, the healthcare industry as a whole, instituted approaches to improving the quality of patient care. Despite this, recent studies have illustrated a lack of progress in this area, indicating that medical errors and adverse events in hospitals, if ranked amongst other diseases, would constitute the third leading cause of death in the US. ${ }^{[2]}$ The fact that adverse clinical events remain such a threat to patient safety is a key consideration calls for examination of clinical practices. Additionally, our efforts directed towards improv- ing patient safety cannot occur in a vacuum. Recent changes to the healthcare system, for instance the Patient Protection and Affordable Care Act, have also required that we consider patient care practices in the context of cost of services provided versus the quality of services.

Falls, injuries and incidences of self-harm are a significant source of complications in US hospitals. Patients who are thought to have significant risk of self-harm or injury are often monitored directly by a staff member. These individuals are often referred to as "sitters"; a staff member or volunteer who provides direct and constant observation of a patient. Sitters are commonly used for patients who have delirium, agitation, confusion, personality and mood disorders, current

\footnotetext{
*Correspondence: James Whyte IV; Email: jwhyte@fsucon.org; Address: College of Nursing, The Florida State University, Tallahassee Florida, United States.
}

Published by Sciedu Press 
substance abuse and those believed to be suicidal. They are also used for patients who are unable to follow directions or are non-compliant, are at risk to falls, are elopement risks, are violent, have impaired vision and hearing and are deemed to be at risk of removing medical devices. ${ }^{[3-9]}$ Although most commonly used in hospitals in the United States (U.S.), the practice has been described in hospitals in Saudi Arabia, Australia, Scotland Canada, and Taiwan. A survey of 102 hospitals revealed that all used some form of sitters to provide direct patient surveillance. ${ }^{[3]}$ A recent study found that $79 \%$ to $100 \%$ of hospitals surveyed utilized sitters although the practice was only instituted in $4 \%$ of patients. ${ }^{[4]}$

The use of sitters as paid individuals is expensive for hospitals. They are most often unlicensed personnel who are reassigned from general nursing care duties to care for one patient. The practice poses a challenge to available staffing resources, and is rarely reimbursed. Costs have been estimated using paid salary dollars, patient length of stay, and estimated savings related to the prevention of adverse outcomes. ${ }^{[3,8]}$ A classic study identified the cost-benefit of a sitter shift at $\$ 3.76$, with a cost of a sitter at $\$ 160.00$, resulting in a net expense of $\$ 156.24 .{ }^{[9]}$ This study provided the groundwork for future studies. More recent studies estimated a cost of $\$ 240.00$ each day for each sitter. ${ }^{[10]}$ In addition, CNOs' have reported that expenses related to the use of sitters accounted for $1 \%$ to $20 \%$ of their salary budget. ${ }^{[11]}$ One unit in a 600-bed hospital reported a monthly cost of $\$ 18,301$ and an estimated annual cost of $\$ 219,612 .{ }^{[4]}$ Hospitals in the United States have reported spending $\$ 500,000$ to over $\$ 2,000,000$ in costs related to sitters. ${ }^{[6,9,12]}$ Clearly, the use of sitters to provide constant surveillance is costly to hospitals.

The literature surrounding the use of sitters and patient outcomes is limited. Recently, there has been a call to closely examine the practice of video monitoring as an alternative to direct patient monitoring by a sitter. ${ }^{[13]}$ Most studies examined patient falls as the outcome and results are conflicting. Boswell, Ramsey, Smith, and Wagner found that a minimal increase in patient falls was associated with each shift of sitter time. They also reported a slight increase in patient satisfaction. Tzeng, Yim, and Grunawalt noted that when sitters were more available on two different units the rate of falls with injuries increased. The authors proposed the increase was due to a higher number of staff members sharing the responsibility of patient care resulting in fragmented workflow. ${ }^{[14]}$ Another study indicated that when the use of sitters decreased, the fall rate also decreased. ${ }^{[15]}$ In this hospital, nurses were reassigned at times to provide constant observation when unlicensed staff was not available. In contrast, three studies identified that falls decreased when sitters were present. ${ }^{[16-18]}$

The literature suggests that a decrease in the use of sitters is possible, while at the same time, maintaining or improving patient safety. ${ }^{[19]}$ These strategies include: symptom triggered practice guidelines that offer early pharmacotherapy management and increased assessments; ${ }^{[20]}$ medical and nursing psychiatric consults or protocols $;^{[3,6,14]}$ and video monitoring. ${ }^{[9,11,19]}$ The use of unpaid adults who volunteered or who were family/friends has been found to be cost effective, however, the reliance of volunteers to staff units around the clock is difficult, ${ }^{[16,21]}$ Goodlett, Robinson, Carson, and Landry noted that when in-room sitters were replaced with video monitoring, the fall rate decreased by $6 \%$, although the difference was not statistically significant. ${ }^{[10]}$ The authors did not state why they felt the falls decreased with video monitoring. The financial savings with video monitoring were significant.

Despite the wide spread use of sitters, there is limited evidence regarding the effects of their use as a strategy for improving patient safety. ${ }^{[6,10,14,22]}$ As such, it is important for nurses to consider less expensive interventions that have demonstrated success in preventing harm such as symptom triggered protocols, staff education, and video monitoring. ${ }^{\text {[9] }}$

The intervention implemented in the hospital where the current study was performed, was engaged to decrease the use of sitters in the study hospital was video monitoring. The same video monitoring equipment employed by the hospital security department was used for this project. Twelve units designated 6-16 beds that would have a ceiling mounted camera installed at the foot of each bed. The camera was wired to a central console at the nurses' station. The central console was located in close proximity to the designated patient rooms and was observed continuously by a trained, unlicensed staff member for four hours at a time. The staff member assigned to the monitors would immediately go to the room if he/she noticed anything of concern such as the patient attempting to get out of bed. When the staff member responded to a patient room, another staff member monitored the central console until he/she returned. The purpose of the current study was to determine the effect of using sitters versus video monitoring on overall patient safety.

The aims of this study were to:

(1) Determine the prevalence of falls using in room sitters and video monitoring.

(2) Determine the prevalence of self-harm using in room sitters and video monitoring.

(3) Determine the cost associated with in room sitters and video monitoring. 


\section{MethodS}

\subsection{Design, Setting, and Sample}

A quasi-experimental, $4 \times 8$ design series with nonrandomized, consecutive sampling was used. The setting was a large, not-for profit, teaching facility in West Central Florida. Participants included adult medical surgical patients 18 years of age or older admitted to either the Cardiology unit or the Neuroscience unit during the designated three biannual 4 month periods, for a total of 4 years of data collection. The Cardiology department offered cardiac telemetry, pre and post cardiac catheterization care, and heart transplant evaluations. The 44-bed Neuroscience department offered medical telemetry, long term seizure monitoring, and care for both neurosurgical and neurology patients, with semi-private and private rooms. The study was approved as exempt by the Institutional Review Board and was granted a waiver of the informed consent process. The University Human Subjects Committee approved the study with purview over the project.

\subsection{Measures}

Falls were defined as an unplanned descent to a lower level when a staff member was not with the patient. This variable was measured as falls per 1,000 patient days. Self-harm events were defined as patient actions with actual or potential to cause self-harm and included self-medication, adjustment of intravenous fluids, and suicidal gestures. Costs included total salary dollars, non-licensed hours and dollars, and average hourly base rates. Costs were calculated as individual patient cost when receiving sitter service, and as organizational cost for providing the service. Video monitoring was defined as continual observation of 1-16 patients at a central console on the unit. In room sitters were defined as one staff member in a room who provided constant observation of 1-2 patients.

\subsection{Data collection}

Data were collected on a monthly basis. Patient falls and selfharm events were obtained from the hospitals risk management department. Cost data and patient days were obtained from the hospital's Finance Decision Support system.

\section{RESUltS}

Statistical analysis was performed using descriptive statistics with standard deviation and independent samples $t$ tests. Table 1 (Cardiology unit) and Table 2 (Neuroscience unit) present a comprehensive analysis of the data for each of the time points, reflecting on direct sitter observation and observation using video monitoring technology. There were no statistically significant differences in the number of patient fall events for either unit. In addition, there was no significant difference in the unit prevalence of falls when in-room sitters or video monitoring was provided as a safety intervention for patients. However, the data reflected a decreasing trend in falls per 1,000 patient days for each unit after video monitoring was implemented. A second aim of this study was to evaluate the occurrence of self-harm events. Inferential statistics could not be performed due to the rareness of events of self-harm attempts. There were a total of three self-harm events for patients on video monitoring. In year 4 , one unit identified two patients attempting self-medication and the other unit observed one patient attempting to self-medicate. Staff members were able to intervene in each occurrence to prevent the self-medication event from occurring.

Total salary dollars, non-licensed hours and dollars, and average hourly base rates were evaluated for each unit. Costs were calculated as per patient cost when receiving sitter service, and an organizational cost for providing the service. Unit one decreased the available beds in 2011, which decreased the number of staff required for patient care. This unit had a statistically significant decrease $(p<.05)$ in the total number of patients monitored by video or sitter in year 4 as a result of dividing the unit in half.

Both units observed a significantly higher $(p<.001)$ number of video monitored patient care interventions than sitters due to a change in practice and policy at the organization. Both units were able to eliminate the use of unlicensed paid staff members to provide sitter services after video monitoring was implemented (see Tables 1 and 2). Unit two had a significant increase $(p<.001)$ in year 2 , and $(p<.05)$ in year 4 total patient days with video or in-room sitters and significantly lower $(p<.05)$ sitter days to provide the video or in-room service, which reveals that more patients were constantly observed by fewer staff members. In year 4 unit one demonstrated a significantly lower $(p<.05)$ monthly expense for sitters estimated at the base rate for Certified Nursing Assistants (CNAs). Unit two demonstrated a significantly lower ( $p$ $<.05)$ in both year 2 and year 4 monthly expense for sitters estimated at the base rate for PCTs. Both units experienced a significant decrease $(p<.05)$ in non-licensed overtime hours and dollars when they instituted video monitoring.

The estimated salary dollars per sitter days decreased in both units. Unit one had significantly lower estimated salary dollars per sitter day $(p<.001)$ in year 2 , and $(p<.05)$ in year 4. Unit two had a significantly lower $(p<.001)$ estimated salary dollars per sitter days in both years 2 and 3. Table 3 demonstrates that the actual average salary dollar per sitter day for each unit decreased after the implementation of video monitoring. 
Table 1. Unit One: A Cardiac Unit

\begin{tabular}{|c|c|c|c|}
\hline Variable & Baseline & Year 2 & Year 4 \\
\hline Patient Days per month & $1,444.75$ (SD 54.66) & $1,449.25(\mathrm{SD} 37.96)$ & 847.00 (SD 26.81) \\
\hline Average daily census & 47.79 (SD 1.77) & 47.93 (SD 0.96) & 27.33 (SD .86) \\
\hline Average Age of All Patients & $60.63(\mathrm{SD} .25)$ & $57.13(\mathrm{SD} .48) * *$ & $55.13(\mathrm{SD} .63) * *$ \\
\hline Number of patient days with an in room sitter & 104.00 (SD 44.27) & $7.88(\mathrm{SD} 6.86) *$ & $1.13(\mathrm{SD} 1.31) *$ \\
\hline Number of patient days with a video sitter & 0 & $121.00(\mathrm{SD} 3.83) * *$ & $83.25(\mathrm{SD} 31.12) *$ \\
\hline Number of in room sitter days & 61.86 (SD 21.65) & $7.875(\mathrm{SD} 6.86) *$ & $1.13(\mathrm{SD} 1.31)^{* *}$ \\
\hline Number of video sitter days & 0 & $30.25(\mathrm{SD} .96) * *$ & $30.25(\mathrm{SD} .96) * *$ \\
\hline Total Pt days with video and in room sitters & 104.00 (SD 44.27) & 128.88 (SD 8.98) & 84.38 (SD 31.31) \\
\hline Total sitter days providing video and in room monitoring & $61.88(\mathrm{SD} 21.65)$ & 38.13 (SD 7.26) & $31.38(\mathrm{SD} 1.49) *$ \\
\hline Number of unit falls & 4.25 (SD 2.75) & 6.25 (SD 3.77) & 1.25 (SD 1.50) \\
\hline Number of patients that fell that month & 3.75 (SD 2.22) & 6.00 (SD 3.74) & 0 \\
\hline Total direct budgeted HPPD & $7.40(\mathrm{SD} .00)$ & 7.20 (SD0.00) & 7.20 (SD 0.00) \\
\hline Non-licensed OT hours & 507.00 (SD 228.14 & $195.00(\mathrm{SD} 21.18) *$ & $66.75(\mathrm{SD} 56.35) *$ \\
\hline RN LPN hours & 9,015.25 (SD 538.99) & 8,937.75 (SD 500.45) & 5,712.75 (SD 92.26) \\
\hline Non-licensed hours & 6,148.25 (SD 818.80) & $5,123.00$ (SD 613.28) & 3,943.50 (SD 104.93) * \\
\hline Total Productive Direct Care Hour & $15,163.50(\mathrm{SD} 1,227.04)$ & $14,062.75$ (SD 780.64) & 9,656.25 (SD 141.81) \\
\hline RN HPPD & $6.23(\mathrm{SD} .37)$ & $6.18(\mathrm{SD} .22)$ & $6.75(\mathrm{SD} .25)$ \\
\hline Non-licensed HPPD & 4.23 (SD .49) & 3.55 (SD .42) & 4.68 (SD .22) \\
\hline Total HPPD & $10.50(\mathrm{SD} .76)$ & 9.70 (SD .48) & 11.40 (SD .42) \\
\hline Monthly expense for sitters estimated with PCT AHR (no OT) & $17,255.70($ SD 6,036.72) & $10,632.30($ SD 2,025.08) & 8,749.86 (SD 416.38) * \\
\hline Estimated Salary dollars per sitter day at PCT base rate & $172.58(\mathrm{SD} 21.05)$ & $82.00(\mathrm{SD} 10.44)^{* *}$ & $112.19(\mathrm{SD} 30.99) *$ \\
\hline
\end{tabular}

Table 2. Unit Two: A Neuroscience Unit

\begin{tabular}{|c|c|c|c|}
\hline Variable & Baseline & Year 2 & Year 4 \\
\hline Patient Days per month & $1,036.51($ SD 35.21) & 992.59 (SD 42.49) & $1,202.03(\mathrm{SD} 43.06))^{* *}$ \\
\hline Average daily census & 34.58 (SD 1.26) & 33.10 (SD .53) & $40.13(\mathrm{SD} 2.17) *$ \\
\hline Average Age of All Patients & 55.38 (SD .75) & 55.63 (SD 1.55) & 46.88 (SD 1.25) \\
\hline Number of patient days with an in room sitter & 114.50 (SD 8.66) & $1.25(\mathrm{SD} 1.50) * *$ & $.25(\mathrm{SD} .50)^{* *}$ \\
\hline Number of patient days with a video sitter & 0 & $164.25($ SD 11.35) ** & $163.50(\mathrm{SD} 19.84) * *$ \\
\hline Number of in room sitter days & 45.00 (SD 5.72) & $1.00(\mathrm{SD} 1.15) * *$ & $.29(\mathrm{SD} .48) * *$ \\
\hline Number of video sitter days & 0 & $30.25($ SD .96) ** & $30.25(\mathrm{SD} .96) * *$ \\
\hline Total Pt days with video or in room sitters & 114.50 (SD 8.66) & $165.50(\mathrm{SD} 12.40) * *$ & $163.75(\mathrm{SD} 20.30) *$ \\
\hline Total sitter days providing video and in room monitoring & 45.00 (SD 5.72) & $31.25(\mathrm{SD} 1.71)^{*}$ & $30.54(\mathrm{SD} 1.27) *$ \\
\hline Number of unit falls & $6.50(\mathrm{SD} 2.65)$ & 8.25 (SD 2.50) & $6.00($ SD 2.94) \\
\hline Number of patients that fell that month & $6.25(\mathrm{SD} 2.50)$ & 7.50 (SD 1.73) & $5.25(\mathrm{SD} 2.22)$ \\
\hline $\begin{array}{l}\text { Number of patients that attempted to self medicate or self harm } \\
\text { event }\end{array}$ & 0 & 0 & $.50(\mathrm{SD} .58)$ \\
\hline $\begin{array}{l}\text { Number of patients that were rescued from self harm event by video } \\
\text { sitter }\end{array}$ & 0 & 0 & $.50(\mathrm{SD} .58)$ \\
\hline Total direct budgeted HPPD & 7.20 (SD 00) & 7.20 (SD 00) & $7.20(\mathrm{SD} .00)$ \\
\hline Non-licensed OT hours & 576.75 (SD 95.40) & $267.75($ SD 151.32) * & $324.25(\mathrm{SD} 160.28) *$ \\
\hline RN LPN hours & 6,909.75 (SD 550.87) & $6,665.25$ (SD 444.01) & $7,871.50$ (SD 209.40) \\
\hline Non-licensed hours & $5,346.50$ (SD 333.19) & $4,880.00($ SD 266.81) & 4,869.50 (SD 253.22) \\
\hline Total Productive Direct Care Hour & $12,256.25$ (SD 461.45) & $11,545.25$ (SD 683.80) & $12,741.00(\mathrm{SD} 409.48)$ \\
\hline RN HPPD & $6.68(\mathrm{SD} .62)$ & $6.73(\mathrm{SD} .22)$ & $6.53(\mathrm{SD} .13)$ \\
\hline Non-licensed HPPD & $5.15(\mathrm{SD} .26)$ & 4.90 (SD .18) & $4.03(\mathrm{SD} .22) * *$ \\
\hline Total HPPD & $11.83(\mathrm{SD} .57)$ & $11.63(\mathrm{SD} .43)$ & $10.58(\mathrm{SD} .34) *$ \\
\hline Monthly expense for sitters estimated at base rate for PCT & $\begin{array}{l}12,549.60(\mathrm{SD} \\
1,593.93)\end{array}$ & $\begin{array}{l}\text { 8,715.00 (SD 476.28) } \\
*\end{array}$ & $5,716.99(\mathrm{SD} 354.93) *$ \\
\hline Estimated Salary dollars per sitter day at PCT base rate & 110.34 (SD 18.96) & $52.75(\mathrm{SD} 2.28) * *$ & $52.47(\mathrm{SD} 5.31) * *$ \\
\hline
\end{tabular}


Table 3. Estimated average salary dollars per patient sitter day

\begin{tabular}{llll}
\hline & Baseline & Year 2 & Year 4 \\
\hline Average Base Rate for PCT & $\$ 11.62$ & $\$ 12.21$ & $\$ 12.83$ \\
Unit I & $\$ 172.58$ & $\$ 82.00$ & $\$ 112.19$ \\
Unit II & $\$ 110.34$ & $\$ 52.74$ & $\$ 52.47$ \\
\hline
\end{tabular}

\section{Discussion}

This study addressed the three general aims; to determine the prevalence of patient falls and self-harm using in-room sitters and video monitoring, and to determine the cost associated with each. Sitters were exclusively used in year 1 for constant observation, and video monitoring was the prevailing method of providing constant observation in the two units for years 2 and 3. This practice is widely used in hospitals. The University Health Consortium (UHC) recently published guidelines for the use of sitters from over 16 academic medical centers. ${ }^{[23]}$ These documents describe the use of sitters as an intervention to prevent patient falls and protect patients from self-harm. Findings of this study did not demonstrate any differences in fall rates in either unit when comparing in-room sitters with video monitoring sitters. However, both units were able to demonstrate a downward trend in falls per 1,000 patient days for the three years reviewed. Similar findings have been reported by other authors. ${ }^{[1,24,25]}$ The UHC provides decision-making processes that nurses apply when determining the need for a sitter to protect a patient from self-harm during hospitalization. This study was unable to evaluate self-harm events when sitters or video monitoring was used due to the rareness of these events.

The third aim of this study was to evaluate the cost difference between the practice of in-room sitters and video monitoring sitters to provide constant observation services. Findings revealed a significant decrease $(p<.001)$ in salary cost per patient sitter day without a significant increase in patient falls or self-harm events when video monitoring was used on a unit for the majority of patients requiring constant observation. The units were able to increase or decrease the number of patients provided constant monitoring without increasing the need for additional staff. Three other acute care hospitals that reported pilot projects using video monitoring were able to demonstrate a cost savings. ${ }^{[1,24,25]}$ The cost savings at the facility annually was over $\$ 500,000$ in the first year, and annually since year 1 . This study is important as findings suggest that nurses can provide lower cost care without a risk to patient safety by using video monitoring instead of in-room sitters.

\section{Limitations}

There are several limitations to this study. The study design included analysis of retrospective data that was obtained from hospital databases that were not created for research purposes. The pre-intervention evaluation period dates back to a time when video monitoring was widely implemented in the study institution. In years 2 and 3 the use of in-room sitters occurred rarely in the two units evaluated. Author bias is also a limitation due to the primary researcher for this study was responsible for implementing video monitoring at the organization. The reporting of patient falls and self-harm is tracked electronically through a voluntary reporting process and under reporting is possible. The specific sitter salary dollars are unable to be isolated due to the individuals that provided the sitter services are the same population of employees that serve as the unlicensed care on each unit. Other factors that may influence patient safety such as purposeful rounding and patient education were not accounted for in this study. In addition, the institutions fall prevention program was revised during the dates the data was collected. It is possible that these changes may have influenced fall rates. These limitations weaken the ability to generalize findings of this study. This study used existing data sets that were not created for the purpose of research. Sampling an measurement errors are characteristic of these data sets and my lessen the internal validity of findings.

\section{Conclusion}

A widespread practice in adult, medical-surgical nursing units is using in-room sitters for patients at risk of self-harm or falling. The cost of providing this monitoring is expensive and not supported by a strong body of evidence. The results of this study support a lower cost nursing practice that does not impose a patient safety risk for falls or selfharm associated with the implementation of video monitoring. Evaluating the perception of staff and patients related to the use of video monitoring is beyond the scope of this study and could be a potential qualitative study. The trend in falls per 1,000 patient days demonstrated a slight decrease. This is an important factor and this review was unable to distinguish the cause of this trend since other interventions were also implemented in the four years of data that was reviewed. Future studies that evaluate the effectiveness of other interventions that prevent patient falls and self-harm events are necessary as we continue to require cost-effective alternatives for patient care in the practice of nursing.

\section{Conflicts of InTerest Disclosure}

The authors declare that there is no conflict of interest. 


\section{REFERENCES}

[1] Kohn LT, Corrigan JM, Donaldson M. To err is human: Building a safer health system. Washington, DC: Institute of Medicine; 1999.

[2] Makary MA, Daniel M. Medical error-the third leading cause of death in the US. BMJ, 2016. 353. epub ahead of print

[3] Worley L, Kunkel E, Gitlin D, et al. Constant observation practices in the general hospital setting. Psychosomatics. 2000; 41(4): 301310. PMid:10906352 http://dx.doi.org/10.1176/appi.psy . 41.4 .301

[4] Rochefort C, Ward L, Ritchie J, et al. Registered nurses' job demands in relation to sitter use. Nursing Research. 2011; 60(4): 221230. PMid:21691242 http://dx.doi .org/10.1097/NNR . Ob013 e318221b6ce

[5] Goldberg R. Use of constant observation in general hospitals. International Journal of Psychiatry in Medicine. 1986; 19(2): 193-201. http://dx.doi .org/10.2190/TU5Y-A86B-FRHT-ERDH

[6] Nadler-Moodie M, Burnell L, Fries J, et al. A S.A.F.E. alternative to sitters. Nursing Management. 2009; (August): 43-50.

[7] Blumenfield M, Milazzo J, Orlowski B. Constant observation in the general hospital. Psychosomatics. 2000; 41(4): 289293. PMid:10906350 http://dx.doi.org/10.1176/appi.psy . 41.4 .289

[8] Rausch D, Bjorklund P. Decreasing the costs of constant observation. Journal of Nursing Administration. 2010; 40(2): $75-$ 81. PMid:20124960 http://dx.doi.org/10.1097/NNA.0b013 e3181cb9f56

[9] Boswell D, Ramsey J, Smith M, et al. Cost-effectiveness of a patient-sitter program in an acute care hospital: A test of the impact of sitters on the incidence of falls and patient satisfaction. Quality Management in Health Care. 2001; 10(1): 10-16. http: //dx.doi.org/10.1097/00019514-200110010-00003

[10] Goodlett D, Robinson C, Carson P, et al. Focusing on video surveillance to reduce falls. Nursing. 2009; 39(2): 201. PMid:19158627 http://dx.doi.org/10.1097/01. NURSE. 00 00345233.09590 .79

[11] Rochefort C, Ward L, Ritchie J, et al. Patient and nurse staffing characteristics associated with high sitter use costs. Journal of Advanced Nursing. 2012; 68(8): 1758-1767. PMid:22050594 http: //dx.doi.org/10.1111/j.1365-2648.2011.05864.x

[12] Al-Asmary S, Al-Shehri A, Al-Omari F, et al. Pattern of use and impact of patient sitters on the quality of healthcare in Saudi Arabia. Saudi Medical Journal. 2010; 31(6): 688-694.

[13] Sand J, Johnson J, Tylka, S. Protecting Patient Safety: Can Video Monitoring Prevent Falls in High-Risk Patient Populations? Journal of Nursing Care Quality. 2016; 31(2): 131-138. PMid:26513398 http://dx.doi.org/10.1097/NCQ.0000000000000163

[14] Tzeng H, Yin C, Grunawalt J. Effective assessment of use of sitters by nurses in inpatient care settings. Journal of Advanced Nursing. 2008; 64(2): 176-183. PMid:18990098 http://dx.doi.org/10. 1111/j.1365-2648.2008.04779.x

[15] Weeks S. Reducing sitter use: Decisions outcomes. Nursing Management. 2011; 42(12): 37-38. PMid:22124299 http://dx.doi.org /10.1097/01. NUMA .0000407582.12602.21

[16] Leger D. Management of Practice Committee. Massachusetts Organization of Nurse Executives: Strategies to minimize the use of sitters: 2010; Survey results. Available from: http://monedev.org/pdf / Sitter_survey.pdf

[17] Davis J. Implementation of video monitoring to decrease 1:1/sitter costs. Paper presented at the 2010 NDNQI Database Use Conference, Rhythms in Quality, New Orleans, LA. Available from: http://an a. confex.com/ana/ndnqi10/webprogram/Paper3461.html

[18] Donoghue J, Graham J, Mitten-Lewis S, et al. Volunteer companionobserver intervention reduces falls on an acute aged care ward. International Journal of Health Care Quality Assurance. 2005; 18(1): 24-31. http://dx.doi.org/10.1108/09526860510576947

[19] Giles L, Bolch D, Rouvray R, et al. Can volunteer companions prevent falls among inpatients? A feasibility study using a pre-post comparative design. BMC Geriatric. 2006; 6(11)

[20] Wright K. Falling head over heels. Reducing falls in high risk neurosurgical inpatients with the implementation of a high risk falls rooms. Australasian Journal of Neuroscience. 2006; 18(1): 3-7.

[21] Borges P, Nourani-Vatani N. Visual-based detection of unusually patient activity. Studies in Health Technology and Informatics. 2011; 168: 16-23. PMid:21893907

[22] Stanley K, Worrall C, Lunsford S, et al. Efficacy of a symptomtriggered practice guideline for managing alcohol withdrawal syndrome in an academic medical center. Journal of Addictions Nursing. 2007; 18: 207-216. http://dx.doi.org/10.1080/108846007 01699255

[23] Harding A. Observation assistants: Sitter effectiveness and industry measures. Nursing Economics. 2010; 28(5): 330-336. PMid:21158254

[24] Jeffers S, Searcey P, Boyle K, et al. Centralized video monitoring for patient safety: A Denver Health Lean journey. Nursing Economics. 2013; 31(6): 298-306.

[25] University of Utah Health Care. 10 Creative nursing ideas that helped transform an entire health system. 2011: Salt Lake City: Nursing Innovation. 